\title{
Hope: A Health Promotion Resource
}

\author{
Tone Rustøen
}

\section{Abstract}

Hope is a phenomenon many nurses and patients are concerned about. One of the reasons for this interest may be that many patients today live with chronic illnesses, and hope is something positive and focuses on the future and opportunities. Hope is a way of feeling, thinking, and influencing one's behavior. The way we view our health and health-related challenges are assumed to impact on hope. Hope is forward-looking, realistic, and multidimensional. It is a resource for health and health-promoting processes and can be considered a salutogenic resource and construct. This chapter highlights what hope means during illness, what research has so far been concerned with, how hope can be assessed, and how nurses can strengthen hope in patients.

\section{Keywords}

Definitions of hope $\cdot$ Hope measurement . Hope interventions

T. Rustøen $(\bowtie)$

Division of Emergencies and Critical Care, Department of Research and Development, Oslo University Hospital HF, Oslo, Norway

Faculty of Medicine, Institute of Health and Society, University of Oslo, Oslo, Norway

e-mail: tone.rustoen@medisin.uio.no

\subsection{The Significance of Hope for Patients with Long- Lasting Illnesses}

Patients with a variety of illnesses describe the importance of hope when being ill or feeling threatened in essential areas of life. A Swedish nurse, Eva Benzein, interviewed people with cancer who received palliative home care about hope [1]. Participants in this study described hope of being cured even though they knew they were seriously ill, hope of living as normally as possible, the importance of the presence of affirmative relationships (family and friends, health professionals or of a more spiritual nature), and a reconciliation with life and death. Everyone expressed that their lives changed dramatically when they learned that no curative treatment was possible. They expressed that they wanted to find a meaning in their situation and expressed that if hope disappears you have nothing. Even if this study is some years old, Benzein's study is central in this research field presenting palliative patient's experiences of hope clearly and interestingly.

Worldwide, the number of intensive care unit admissions and survivors after treatment in intensive care is increasing $[2,3]$ due to an aging population and advances in critical care medicine. Several patients admitted to an intensive care unit have a chronic condition. When being critically ill the future can be uncertain both related to survival, recovery, and daily functioning. A former 
intensive care patient shared her experiences as critically ill, describing hope to be essential for her recovery [4]. Possibly, an ICU patient's goal is to maintain one's hope during serious illness and recovery. Little research is done on hope in ICU patients.

Hope is an effective coping strategy for patients in demanding life situations [5]; it provides adaptive power for getting through difficult situations and achieving meaning and desired goals $[1,6]$. It is described to generate energy, often described as "will," with a motivational quality [5]. It can be a resource that provides strength to master a disorder. It has also been shown that hope is central to one's quality of life [7]. Erich Fromm argues that hope is absolutely essential to life [8].

Hope is also described to act as a psychosocial resource to deal with chronic illness experiences in a meta-analyses about hope in those above 60 years with chronic illnesses [9]. In this metaanalyses the participants explained that a sense of self, feelings of control, relationships with others, and quality of life were associated with hope. Accordingly, hope is part of the generalized resistance resources, important for health promotion and for salutogenic nursing.

\subsection{Theoretical Perspectives of Hope}

First, this chapter shows some central and frequently used definitions of hope, followed by a description of spheres and dimensions of hope. All these three descriptions of hope contribute to a deeper understanding of the essence of hope as a salutogenic construct and perceived experience.

\subsubsection{Definitions of Hope}

Hope is a complex phenomenon that is studied in several disciplines. It is also defined as a basic confidence in and feeling that there is a way out of one's difficulties [10]. Joyce Travelbee defined hope as a mental state characterized by the desire to reach a goal, combined with some degree of expectation that this goal is achievable [11]. Hope is also defined as a positive motivational state based on setting goals and thinking about ways to reach them $[12,13]$. The hope literature emphasizes both the emotional and the cognitive aspects.

Dufault and Martocchio [14] published a definition of hope 30 years ago, and this definition is still often referred to. They defined hope as "a multidimensional dynamic life force characterized by a confident yet uncertain expectation of achieving a future good which, to the hoping person, is realistically possible and personally significant" (p. 380). This definition emphasizes that hope represents a dynamic life force. There are strengths in hope, understood as forces to move forward even if you face resistance. Dufault and Martocchio also show the versatility of hope and that hope should be both realistic and important. That hope should be realistic is also emphasized by Travelbee [11]. Fromm [8] wrote that "hope is neither passive waiting nor is it unrealistic forcing of circumstances that cannot occur" (p. 22). He also stated that there is "no sense in hoping for that which already exists or for that which cannot be" (p. 22). Many definitions of hope as the one given by Dufault and Martocchio [14] have in common that hope is considered to be forward-looking, realistic, and multidimensional.

Farran and colleagues [15] have conducted a literature review of studies about hope. Based on this review, hope is defined as follows:

\begin{abstract}
Hope constitutes an essential experience of the human condition. It functions as a way of feeling, a way of thinking, a way of behaving, a way of relating to oneself and one's world. Hope has the ability to be fluid in expectations, and in the event that the desired object or outcome does not occur, hope can still be present. (p. 6)
\end{abstract}

Through the definitions and descriptions of the content of hope, it emerges that hope is a way of feeling and thinking which influences one's behavior. Within the hope literature, there is a debate about whether hope is a more or less stable state in a person or whether hope is a dynamic process that changes over time [16]. There are 
reasons to believe that personal qualities matter but that hope is influenced by what we encounter. This will be illuminated somewhat more in the section describing different dimensions of hope.

Kim and colleagues [16] studied the nature of hope in chronically ill people. They conducted an interview study of 12 hospitalized chronically ill patients from the United States and 16 nurses working in oncology departments. Everyone was asked to reflect on hope. Different patterns of subjective experiences of hope were described: (1) an externalism orientation, (2) a pragmatism orientation, (3) reality orientation, (4) future orientation, and lastly, (5) an internalism orientation.

Those who described an externalism orientation said that their sources of hope were different from themselves, such as God or significant others. They put a lot in God's hands, and they trusted family and friends to help them. Their own efforts were not important.

In a pragmatic orientation, the chronically ill patients stated that they found the source of hope by doing small things or enjoying things they can accomplish. Patients who fell into this pattern stated that they did not believe in the major goals as they had no belief that they could be achieved. They had accepted their illness without the prospects of getting better, and they experienced hope by having a positive attitude toward the future as well as the present.

The chronically ill with a reality-oriented orientation experienced hope through a sober perception of their situation. Their view of the future was thoroughly grounded in relation to the realities of their illness. They also described God as a stable and important force in life.

Patients in the future orientation category experienced hope by planning the future and ensuring that it contained positive opportunities. They also had a strong dependence on God. These patients do not perceive hope in relation to what other people may think but argue that everything that happens have a reason.

Patients who had an internalism orientation experienced hope through humor or related to advances in science. This type of hope was based on the patient's belief in what was possible in their situation, on their own actions, on the use of humor, knowledge, or the presence of family or friends. This kind of hope was not perceived in relation to opportunities in the future or by leaving it to other people, but on the patient's own perception of the situation in question.

The researchers summarize this study by pointing out that different chronically ill patients focus on different sources of hope, and thus experience hope differently. The hope patterns described may differ due to the different characteristics of the patients. The importance of the relationship with God was highlighted in most of the different orientations. In which ways these patterns are related to health promotion and salutogenesis is not known yet.

In a literature review on hope in qualitative studies, Duggleby and colleagues summarized the characteristics of hope [9] and described two hope-processes: (1) transcendence and (2) reappraisal in re-evaluating hope when being chronically ill. Reaching inwardly and outwardly and finding meaning and purpose were sub-processes of transcendence, whereas re-evaluating hope in the context of illness and finding positive possibilities were sub-processes of positive reappraisal. These two processes are integrated. However, Duggleby and colleagues [17] concluded that hope in older persons with chronic illness involves transcendence from a difficult situation and positive reappraisal. If you cannot get rid of the chronic illness and its consequences, you can always change the way you think about your situation.

The concepts presented by Duggleby et al. [17] are central for sense of coherence and salutogenesis [18]. Still, the relationship between hope and sense of coherence is scarcely examined. In a Norwegian sample of intensive care patients 3 months after discharge from the intensive care unit, we found the correlation between hope (measured using Herth Hope Index) and sense of coherence (measured by Antonovsky's sense of coherence scale) was 0.56 , meaningfulness and hope was 0.44 , comprehensibility and hope was 0.45 , and manageability and hope was 0.44 (unpublished data). These results suggest that hope and sense of coherence are moderately 
correlated in Norwegian intensive care survivors. In a study from Israel in three different cultural groups, they also concluded that hope and sense of coherence stand as separate resources even if the concepts have some overlap [19]. Møllenberg et al. showed that a stronger family sense of coherence was associated with higher hope in both persons with cancer and their family members [20]. Further research is warranted to examine the health-promoting aspects of hope.

\subsubsection{Different Spheres and Dimensions of Hope}

Dufault and Martocchio [14] stated that hope consists of two spheres. One sphere is a generalized (or general) hope and the other a particularized (or partial) hope. They defined generalized hope as a feeling that the future is uncertain but can be positive. A general feeling of hope protects the hopeful by casting a positive glow on life. A statement describing this is: "I hope for nothing special, I just hope." The other sphere of hope is the partial hope associated with a particular object that may be abstract or concrete (e.g., a new treatment).

This division of hope into spheres and dimensions was also described in Benzein's study [1] of the patients receiving palliative home care. These patients described hope as a tension between hoping for something (individualized hope) and living in hope (generalized hope). Hoping for something was related to being cured, while living in hope was a reconciliation of life and death. Which of these two spheres are dominating the palliative patient's state is seen to vary during the illness trajectory. An example of the disparity between these two spheres is that if one hopes for a treatment to succeed (individualized hope), one may not fully succumb if the treatment fails because the generalized hope can take over until one might find new particularized hopes.

The generalized hope can be a form of "fundamental" or "existential" hope [21]. A generalized hope is related to our ability to make or find meaning in our lives. A fundamental hope enables us to survive, e.g., loss of meaning.

Several definitions of hope include different dimensions or aspects of hope. Mary Nowotny
[22], based on a comprehensive literature review, has defined hope as consisting of six different dimensions:

a six-dimensional, dynamic attribute of the person which orients to the future, includes involvement by the individual, comes from within, is possible, relates to or involves others or a higher being, and relates to meaningful outcomes to the individual. (p. 89)

Dufault and Martocchio [14] also described that hope has six different dimensions: an affective dimension, a cognitive dimension, a behavioral dimension, an attachment dimension, a time dimension, and a contextual dimension. Based on research using the Dufault and Martocchio hope dimensions, the next section will elaborate on these six dimensions presented by Dufault and Martocchio:

The affective dimension shows the emotional aspect of hope. As already shown, hope is often defined as an emotion, with many different feelings involved. Both confidence in that a positive result is possible and uncertainty about the future are central feelings in hope [23]. Travelbee emphasized both trust and courage as aspects of hope.

The cognitive dimension contains thoughts, ideas, goals, desires, and expectations. This dimension is related to comprehensibility in sense of coherence, which refers to the extent to which you might perceive both internal and external stimuli as being understandable in some kind of rational way [18]. An important factor here is how one assesses his or her opportunities, for example, get well or to have a good quality of life. An evaluation of the reality and hopeful factors will be central. A desire is often defined differently from hope as it may have less realism. This distinction is not easy, but hope is claimed to be based more on basic values such as experiencing community or being active. As one processes a situation, hopes and desires may become more coincidental. Still, wanting something will be part of the hope. Travelbee emphasizes both desire and having choices as important for hope.

The behavioral dimension of hope is related to what actions one takes, such as eating healthy food, praying, or making a decision [14]. This 
dimension is in accordance with manageability in sense of coherence and has to do with the degree to which we might feel that there are resources at our disposal to meet demands [18]. It is pointed out that a hopeful person is better able to act than one who does not experience hope. There is energy in hope. Travelbee [11] points out that hope is linked to perseverance.

The associational dimension highlights the importance of good interpersonal relationships for hope [22]. These can be relationships with other people or with religion. Travelbee [11] claimed that hope is linked to dependence on others. The importance of religiosity for hope will probably differ depending on cultural differences.

The time dimension is fundamental for hope and implies the expectation of being able to achieve something in the future, and will in this way be time-related [14]. Travelbee [11] claims that hope is future-oriented.

Lastly, the contextual dimension concerns that hope is activated within a context. This dimension focuses on the specific circumstances of life that surround, influence, and challenge an individual's hopes. This dimension is the same as specific resistance resources in sense of coherence [18], which is context bounded. Hope is not regarded as a stable trait in man, but as a condition influenced by external factors such as illness and changes in life (depending on context). Consequently, it is very important how patients experience their surroundings when they are seriously ill, facing threats of their life or health. Travelbee [11] argued that nurses must prevent patients from losing their hope. Nurses can influence an individual's hope by caring behavior and the nurse-patient interaction including the way information and support are provided. We can also say that salutogenic nursing care promotes patients' hope, health, and well-being.

\subsubsection{How to Measure Hope}

When it comes to research on hope, the focus is often on how to identify hope using various questionnaires. Some studies have identified hope in different patient groups at different stages of illness. Furthermore, there are several qualitative studies helping to understand patients' experiences of hope [9].

Different questionnaires are developed to identify hope within health disciplines, especially by nursing researchers. Examples of such instruments are Miller Hope Scale [24], Nowotny Hope Scale [22], Stoner Hope Scale [25], Herth Hope Scale [26], and Herth Hope Index [27]. These scales are developed based on different definitions of hope. The Herth Hope Index is based on Daufalt and Martocchio's understanding of hope, which is used in several studies internationally, and found to have satisfactory psychometric properties in many countries. Herth Hope Index consists of 12 items. The answer options range on a 4-point scale from "strongly disagree" to "strongly agree." Table 6.1 shows the content of the 12 items and the scaling.

An advantage of this scale is that it is short and easy to complete [27]; therefore, it is clinically relevant. This questionnaire is currently used in patients with pain, cancer, heart failure, liver failure, cystic fibrosis, nursing home residents, and in relatives of intensive care patients. This scale has also been tested in the normal Norwegian and Swedish population [28, 29]. The instrument has the advantage that it is not specifically aimed at a specific outlook on life. Nowotny Hope Scale, which is also found in a Norwegian translation, gives religious people a higher hope than non-believers [30]. The role of religious beliefs in hope is debated, but I believe that hope will have different content for different individuals depending on one's beliefs.

Since the Herth Hope Index is short and easy to fill in, it can be used in clinical practice. There is always a danger that those patients who have the most difficulties do not contact health professionals for help. An early survey of hope using the Herth Hope Index can help to capture those who have the most difficulty. However, if using this scale in clinical practice, the results must be followed-up by adequate nursing care and actions toward the patient. If you as a health care professional, choose not to use the entire form, you may benefit from looking at the individual questions 
Table 6.1 The Herth Hope Index ${ }^{\mathrm{a}}$ [27]

1. I have a positive outlook toward life

2. I have short and/or long range goals

3. I feel all alone

4. I can see possibilities in the midst of difficulties

5. I have faith that gives me comfort

6. I feel scared about my future

7. I can recall happy/joyful times

8. I have a deep inner strength

9. I am able to give and receive caring/love

10. I have a sense of direction

11. I believe that each day has potential

12. I fell my life has value and worth

aC 1989 Kaye Herth. 1999 items 2 and 4 reworded. (Reprinted with permission of Kay Herth. Cannot be used without permission from Kaye Herth)

in the instrument and using them in conversation with the patient. Based on the patient's assessment of his or her situation, the results could be used as a starting point to talk to the patient about his/her hope and to assess whether the patient could possibly benefit from an intervention in relation to hope. Research has shown that a nurse-patient interaction including listening, acknowledging, respecting, and understanding the patient's experiences is health promoting [31] (see Chap. 10).

\subsubsection{Factors That Can Facilitate or Hinder Hope}

Various studies on different patient groups have examined what facilitates and what hinders hope. An Iranian study on hope and spirituality in patients with cardiovascular diseases, found a stronger hope among those being married, having higher education, good economic status and with stronger spiritual well-being [32]. This study concluded that multiple factors may influence on hope.

Another study on hope in women after cardiac surgery [33] showed that diminished hope was associated with older age, lower education, depression prior to surgery, and persistent pain at all measurement points up to 12 months after surgery. The authors concluded that e.g. promoting hope, particularly for women living alone may be important targets for interventions to improve outcomes following cardiac surgery.
Furthermore, a study examining the relationship between hope, symptoms, needs, and spirituality/religiosity in cancer patients treated in a supportive care unit [34] reported that those with less education, less symptoms, and less often had been referred to a psychologist previously to the study, as well as higher spirituality reported higher hope.

Previous studies on hope assess hope in different patient populations in various clinical and life settings as well as countries; therefore, summarizing factors that facilitate hope based on earlier research is difficult. The use of covariates to examine the impact on hope is also differing from study to study. The research on hope includes patients from different countries; hence, cultural differences might influence the results. As hope seems to be related to spiritual well-being, variations about beliefs and values might also be a disturbing factor. Furthermore, low education and many symptoms seem to negatively impact on hope.

\subsubsection{Health-Promoting Interventions Strengthening Hope}

Knowledge about factors that can strengthen hope in patients is important when developing interventions to impact on patients' hope. Research on factors strengthening hope is limited; however, there are reasons to believe that more research will come when instruments to assess 
hope are available in many countries. Caring for patients with serious illnesses and an uncertain future can be a challenge. Nurses are around patients and they are important in strengthening or maintain hope. Travelbee writes [11]:

The job of the professional nurse is to help the sick to maintain hope and avoid hopelessness.... (p. 123)

One must be open to the fact that there are many ways of promoting hope. It can be helpful to let patients put their own words into how they look at the time they have ahead. It can be a gateway to talk about hope (see Chap. 10). As Travelbee writes, the nurse's behavior can mean a lot to patients' hopes. The fact that one dares to be present and listen to the patient is emphasized, and the patient must have confidence in the nurse.

An interview study explored critical care nurses' perceptions of hope inspiring strategies in adult patients and families [35]. The nurses told that communication was the major theme for intervention (see Chap. 10). Listening, asking questions, and educate were described. Nurses stressed to be honest and a large part of communication was getting to know the patient as a person which is an essence in nurse-patient interaction and salutogenic nursing care. They also emphasized that it was important to incorporate family into care.

The nurse-patient interaction is shown to be important for hope in cognitively intact nursing home residents [31]. Haugan et al. [36] found a direct relationship of nurse-patient interaction on hope, meaning in life and self-transcendence, and conclude that advancing caregivers' interacting and communicating skills might facilitate patients' health and global well-being and inspire professional caregivers as they perform their daily care practices.

Frankl wrote about the importance of finding hope and meaning in life, suggesting selftranscendence as the process of reaching out beyond oneself and thus discover meaning in life [37] (see Chap. 8). A way to find meaning is through the chosen attitude when faced with an unchangeable situation. Duggleby and colleagues claimed that hope is a psychosocial resource which individuals use to deal with their chronic illness experience [9]. Finding meaning and positive reappraisals are important strategies to help older adults with chronic illnesses to maintain their hope. Ways to foster hope with older adults with chronic illness may include strategies for finding meaning and purpose which is a process of self-transcendence [9] (see Chap. 9). Strategies such as adjustment to transitions and losses, life review, reminiscence therapy, and spiritual support can help people find meaning and purpose and transcend their experience of suffering (see Chap. 8).

Ripamonti and colleagues [34] conclude that in cancer patients, hope can be encouraged by clinicians through dialog, sincerity, and reassurance, as well as assessing and considering the patients' needs (above all the psycho-emotional), symptoms, psychological frailty, and their spiritual/religious resources.

The above-presented studies describe how to strengthen hope in patients; however, they mainly focus on communication and the nurse-patient relationship and the nurse-patient interaction. This is of great importance, but it is not clear what is specific hope inspiring or what is related to other hope-related phenomena.

The effectiveness of a psychosocial supportive intervention to increase hope and quality of life was evaluated in terminally ill cancer patients 60 years and older staying at home [38]. The hope intervention termed "Living with Hope Program" (LWHP) consisted of viewing an international award-winning video on hope and a choice of one of three hope activities to work on over a 1-week period. The control group received standard care. The data were collected at the first visit in the patients' homes. Analyses showed that patients receiving the LWHP had higher hope and quality of life compared to those in the control group. They also collected qualitative data with open-ended hope questions from the treatment group. The qualitative data confirmed the findings from the statistical analyses as $62 \%$ of the patients in the treatment group reporting the LWHP increased their hope.

A recent study described smartphone delivery of a hope intervention to students [39]. The intervention was based on Snyder's theory of hope 
and used text messages with hope stories and pictures. Using a quasi-experimental pilot study with pretest and posttest design, the feasibility and potential impact of the mobile app were examined. The analyses showed that the participants appeared to engage with the intervention and found the experience to be user-friendly, helpful, and enjoyable. Relative to the control group, those receiving the intervention demonstrated a significantly greater increase in hope.

Research should continue to develop interventions to strengthen hope in patients. When choosing an intervention to strengthen hope, the intervention must be based on what is most important for the patient's hopes. The interventions can be individual or group-based. There is a need for studies that can further investigate how hope best can be strengthened in patients also in the specialist health service. Based on earlier research, areas like finding meaning, self-transcendence, nursepatient interaction, and communication are important but seem not specific to hope. To secure that the interventions are related to hope one might talking with the patients about the different aspects included in the 12 items in Herth Hope Index.

A challenge in building the research on strengthening hope is that the studies presented just to a small amount are building on each other. One should base research well in what is already there. Another challenge is that hope might mean different if you are young or elderly, are very ill or in a rehabilitation phase. Further, individual's cultural and religious background impact on the content of their hope. Further research is needed about how to promote hope in different patient groups.

\subsection{Conclusion}

As shown in this chapter, there are many different definitions of hope. Some characteristics are included in several definitions, while other aspects vary from definition to definition. Some emphasize that hope must be realistic in order to be a hope, while others do not include this aspect at all. The degree to which hope is influenced by personal characteristics or by the surroundings is also unclear. Finally, in comparing research on hope between different international studies, the cultural differences important to hope represent a challenge. For example, when it comes to the importance of religion to hope, I expect that this will vary significantly across countries.

Given the importance of hope for patients in a variety of situations, we must continue our efforts to understand hope and to gain greater knowledge of how we can best help to strengthen patients' hope in the best possible way. There are reasons to believe that hope is a central phenomenon for health promotion and salutogenic nursing care.

\section{Take Home Messages}

- Hope is an important phenomenon for many different patient groups.

- Hope is a vital resource for health promotion in healthy as well as unhealthy people and represents a salutogenic concept.

- Hope is defined in different ways, but there is a consensus that hope is a multidimensional concept comprising both feelings and the way of thinking.

- Research on hope has been centered on how hope can be mapped to different patient groups and how hope can be strengthened in meeting patients.

- Hope can be facilitated by communication, nurse-patients interaction, and the individual's ability for self-transcendence.

- Further research is desirable and necessary to better enable the nurse to strengthen the hope of patients.

\section{References}

1. Benzein E, Norberg A, Saveman BI. The meaning of the lived experience of hope in patients with cancer in palliative home care. Palliat Med. 2001;15(2):117-26.

2. Halpern NA, Pastores SM. Critical care medicine in the United States 2000-2005: an analysis of bed numbers, occupancy rates, payer mix, and costs. Crit Care Med. 2010;38(1):65-71.

3. Maca J, Jor O, Holub M, Sklienka P, Bursa F, Burda M, Janout V, Ševčík P. Past and present ARDS mortality rates: a systematic review. Respir Care. 2017;62(1):113-22. 
4. Kjærgård RS. The blink of an eye: how I died an started living. 2019 Hodder \& Stoughton.

5. Folkman S. Stress, coping, and hope. Psychooncology. 2010;19(9):901-8.

6 . Herth K. Enhancing hope in people with a first recurrence of cancer. J Adv Nurs. 2000;32(6):1431-41.

7. Rustøen T, Cooper BA, Miaskowski C. The importance of hope as a mediator of psychological distress and life satisfaction in a community sample of cancer patients. Cancer Nurs. 2010;33(4):258-67.

8. Fromm E. The revolution of hope, toward a humanized technology. 1st ed. New York: Harper \& Row; 1968.

9. Duggleby W, Hicks D, Nekolaichuk C, Holtslander L, Williams A, Chambers T, et al. Hope, older adults, and chronic illness: a metasynthesis of qualitative research. J Adv Nurs. 2012;68(6):1211-23.

10. Lynch W. Images of hope. Notre Dame, IN: University of Notre Dame Press; 1974.

11. Travelbee J. Interpersonal aspects of nursing. Philadelphia: F. A. Davis; 1966. p. xii.

12. Snyder CR, Harris C, Anderson JR, Holleran SA, Irving LM, Sigmon ST, et al. The will and the ways: development and validation of an individualdifferences measure of hope. J Pers Soc Psychol. 1991;60(4):570-85.

13. Snyder OJ. Research our great and only hope. J Am Osteopath Assoc. 2001;101(9):542-4.

14. Dufault K, Martocchio BC. Symposium on compassionate care and the dying experience. Hope: its spheres and dimensions. Nurs Clin North Am. 1985;20(2):379-91.

15. Farran CJ, Wilken C, Popovich JM. Clinical assessment of hope. Issues Ment Health Nurs. 1992;13(2):129-38.

16. Kim DS, Kim HS, Schwartz-Barcott D, Zucker D. The nature of hope in hospitalized chronically ill patients. Int J Nurs Stud. 2006;43(5):547-56.

17. Duggleby W, Bally J, Cooper D, Doell H, Thomas R. Engaging hope: the experiences of male spouses of women with breast cancer. Oncol Nurs Forum. 2012;39(4):400-6.

18. Antonovsky A. Unraveling the mystery of health: how people manage stress and stay well. 1st ed. San Francisco: Jossey-Bass; 1987.

19. Braun-Lewensohn O, Abu-Kaf S, Kalagy T. Are "sense of coherence" and "Hope" related constructs? Examining these concepts in three cultural groups in Israel. Isr J Psychiatry Relat Sci. 2017;54(2): 17-23.

20. Møllerberg ML, Arestedt K, Swahnberg K, Benzein E, Sandgren A. Family sense of coherence and its associations with hope, anxiety and symptoms of depression in persons with cancer in palliative phase and their family members: a cross-sectional study. Palliat Med. 2019;33(10):1310-8.

21. Snow NA. Fundamental hope, meaning and selftranscendence. In: Frey JA, editor. Self-transcendence and virtue: perspectives from philosophy, psychology, and technology. 1st ed. New York: Taylor \& Francis; 2018.

22. Nowotny ML. Assessment of hope in patients with cancer: development of an instrument. Oncol Nurs Forum. 1989;16(1):57-61.

23. Rustøen T, Hanestad BR. Nursing intervention to increase hope in cancer patients. J Clin Nurs. 1998;7(1):19-27.

24. Miller JF, Powers MJ. Development of an instrument to measure hope. Nurs Res. 1988;37(1):6-10.

25. Stoner MH, Keampfer SH. Recalled life expectancy information, phase of illness and hope in cancer patients. Res Nurs Health. 1985;8(3):269-74.

26. Herth K. Development and refinement of an instrument to measure hope. Sch Inq Nurs Pract. 1991;5(1):39-51; discussion 3-6.

27. Herth K. Abbreviated instrument to measure hope: development and psychometric evaluation. J Adv Nurs. 1992;17(10):1251-9.

28. Rustøen T, Wahl AK, Hanestad BR, Lerdal A, Miaskowski C, Moum T. Hope in the general Norwegian population, measured using the Herth Hope index. Palliat Support Care. 2003;1(4): 309-18.

29. Benzein E, Berg A. The Swedish version of Herth Hope index-an instrument for palliative care. Scand J Caring Sci. 2003;17(4):409-15.

30. Rustøen T, Wiklund I. Hope in newly diagnosed patients with cancer. Cancer Nurs. 2000;23(3): 214-9.

31. Haugan G, Moksnes UK, Espnes GA. Nursepatient interaction: a resource for hope in cognitively intact nursing home patients. J Holist Nurs. 2013;31(3):152-63.

32. Yaghoobzadeh A, Soleimani MA, Allen KA, Chan YH, Herth KA. Relationship between spiritual wellbeing and hope in patients with cardiovascular disease. J Relig Health. 2018;57(3):938-50.

33. Bjørnnes AK, Parry M, Lie I, Falk R, Leegaard M, Rustoen $\mathrm{T}$. The association between hope, marital status, depression and persistent pain in men and women following cardiac surgery. BMC Womens Health. 2018;18(1):2.

34. Ripamonti CI, Miccinesi G, Pessi MA, Di Pede P, Ferrari M. Is it possible to encourage hope in nonadvanced cancer patients? We must try. Ann Oncol. 2016;27(3):513-9.

35. Fowler SB. Critical-care nurses' perceptions of hope: original qualitative research. Dimens Crit Care Nurs. 2020;39(2):110-5.

36. Haugan G. Nurse-patient interaction is a resource for hope, meaning in life and self-transcendence in nursing home patients. Scand J Caring Sci. 2014;28(1):74-88.

37. Frankl VE. The will to meaning; foundations and applications of logotherapy. New York: World Pub; 1969. 
38. Duggleby WD, Degner L, Williams A, Wright K, Cooper D, Popkin D, Holtslander L. Living with hope: initial evaluation of a psychosocial hope intervention for older palliative home care patients. J Pain Symptom Manage. 2007;33(3):247-57.
39. Daugherty DA, Runyan JD, Steenbergh TA, Fratzke BJ, Fry BN, Westra E. Smartphone delivery of a hope intervention: another way to flourish. PLoS One. 2018;13(6):e0197930.

Open Access This chapter is licensed under the terms of the Creative Commons Attribution 4.0 International License (http://creativecommons.org/licenses/by/4.0/), which permits use, sharing, adaptation, distribution and reproduction in any medium or format, as long as you give appropriate credit to the original author(s) and the source, provide a link to the Creative Commons license and indicate if changes were made.

The images or other third party material in this chapter are included in the chapter's Creative Commons license, unless indicated otherwise in a credit line to the material. If material is not included in the chapter's Creative Commons license and your intended use is not permitted by statutory regulation or exceeds the permitted use, you will need to obtain permission directly from the copyright holder. 